Article publié par le Laboratoire de Construction en Béton de l'EPFL

\begin{tabular}{|l|l|}
\hline Title: & $\begin{array}{l}\text { On the efficiency of flat slabs strengthening against punching using externally } \\
\text { bonded fibre reinforced polymers }\end{array}$ \\
\hline Authors: & Faria D. M. V., Einpaul J., Ramos A.P., Fernández Ruiz M., Muttoni A. \\
\hline Published in: & Construction and Building Materials \\
\hline DOI & $10.1016 /$ j.conbuildmat.2014.09.084 \\
\hline $\begin{array}{l}\text { Volume: } \\
\text { Pages: }\end{array}$ & $\begin{array}{l}\text { Vol. 73 } \\
\text { pp. 366-377 }\end{array}$ \\
\hline Country: & Netherlands \\
\hline Year of publication: & 2014 \\
\hline Type of publication: & Peer reviewed journal article \\
\hline
\end{tabular}

\begin{tabular}{|l|l|}
\hline Please quote as: & $\begin{array}{l}\text { Faria D. M. V., Einpaul J., Ramos A.P., Fernández Ruiz M., Muttoni A., On the } \\
\text { efficiency of flat slabs strengthening against punching using externally bonded } \\
\text { fibre reinforced polymers, Construction and Building Materials, Vol. 73, } \\
\text { Netherlands, 2014, pp. 366-377. }\end{array}$ \\
\hline
\end{tabular}




\title{
On the efficiency of flat slabs strengthening against punching using externally bonded fibre reinforced polymers
}

\author{
Duarte M. V. Faria $^{\mathrm{a}, *}$, Jürgen Einpaul ${ }^{\mathrm{a}}$, António M. P. Ramos ${ }^{\mathrm{b}}$, Miguel Fernández Ruiz ${ }^{\mathrm{a}}$, Aurelio Muttoni ${ }^{\mathrm{a}}$ \\ ${ }^{a}$ Ecole Polytechnique Fédérale de Lausanne, CH-1015 Lausanne, Switzerland \\ ${ }^{\mathrm{b}}$ UNIC, Department of Civil Engineering, Faculdade de Ciências e Tecnologia, Universidade NOVA de Lisboa, 2829-516 Caparica, Portugal
}

\section{H I G H L I G H T S}

- FRP's can be effectively used to strengthen existing flat slabs against punching shear.

- The CSCT can be applied to predict the punching strength of strengthened slabs using FRP's.

- The strengthening efficiency is more pronounced in slabs with lower reinforcement ratio and larger column sizes.

- The strengthening efficiency is less pronounced in actual continuous flat slabs.

\section{A R T I C L E I N F O}

\section{Article history:}

Received 5 February 2014

Received in revised form 27 August 2014

Accepted 23 September 2014

\section{Keywords:}

Flat slabs

Punching shear

Fibre reinforced polymer strengthening

Continuous slabs

Internal forces redistribution

Construction sequence

Critical Shear Crack Theory

\begin{abstract}
A B S T R A C T
One possibility for strengthening existing flat slabs consists on gluing fibre reinforced polymers (FRPs) at the concrete surface. When applied on top of slab-column connections, this technique allows increasing the flexural stiffness and strength of the slab as well as its punching strength. Nevertheless, the higher punching strength is associated to a reduction on the deformation capacity of the slab-column connection, which can be detrimental for the overall behaviour of the structure (leading to a more brittle behaviour of the system). Design approaches for this strengthening technique are usually based on empirical formulas calibrated on the basis of the tests performed on isolated test specimens. However, some significant topics as the reduction on the deformation capacity or the influence of the whole slab (accounting for the reinforcement at mid-span) on the efficiency of the strengthening are neglected. In this paper, a critical review of this technique for strengthening against punching shear is investigated on the basis of the physical model proposed by the Critical Shear Crack Theory (CSCT). This approach allows taking into account the amount, layout and mechanical behaviour of the bonded FRP's in a consistent manner to estimate the punching strength and deformation capacity of strengthened slabs. The approach is first used to predict the punching strength of available test data, showing a good agreement. Then, it is applied in order to investigate strengthened continuous slabs, considering moment redistribution after concrete cracking and reinforcement yielding. This latter study provides valuable information regarding the differences between the behaviour of isolated test specimens and real strengthened flat slabs. The results show that empirical formulas calibrated on isolated specimens may overestimate the actual performance of FRP's strengthening. Finally, taking advantage of the physical model of the CSCT, the effect of the construction sequence on the punching shear strength is also evaluated, revealing the role of this issue which is also neglected in most empirical approaches.
\end{abstract}

(c) 2014 Elsevier Ltd. All rights reserved.

\section{Introduction}

Fibre Reinforcement Polymers (FRP) can be used as a technique to strengthen existing two way flat slabs against punching shear

\footnotetext{
* Corresponding author.

E-mail addresses: duarte.viulafaria@epfl.ch (D.M. V. Faria), jurgen.einpaul@epfl.ch (J. Einpaul), ampr@fct.unl.pt (A.M. P. Ramos), miguel.fernandezruiz@epfl.ch
} (M. Fernández Ruiz), aurelio.muttoni@epfl.ch (A. Muttoni). failures developing at slab-column connections [1-12]. For this purpose, FRP strips are usually glued on the top surface of the slab (Fig. 1). Different potential failure modes can be governing for members strengthened with FRP's as described in Smith and Teng [13]: (1) FRP rupture, (2) crushing of the compressed concrete, (3) shear failure, (4) concrete cover separation, (5) plate end interfacial debonding and (6) intermediate crack induced interfacial debonding. In this paper, the shear failure mode will be investigated in detail. The influence of FRP reinforcement on the punching shear 
strength is explained in Fig. 2 with the help of the Critical Shear Crack Theory (CSCT) [14]. In Fig. 2a, a conventional reinforced slab (without any FRP strengthening) is presented. Punching failure occurs for a given deformation level (rotation $\psi_{R}$ of the slab at the connection), when the shear demand equals the available shear strength $\left(V_{R}\right)$. According to the CSCT, the shear strength decreases for increasing opening of the flexural cracks (related to the rotation and size of the slab) as wider cracks have a lower capacity to transfer shear stresses. If the member is strengthened during its service life by gluing FRP strips on the surface of the slab (refer to Fig. 2b), the flexural behaviour would be stiffer (lower crack openings developing for the same level of load) and thus the punching shear strength can potentially be increased $\left(V_{R, s t}\right)$. It is to be noted that the increase on the flexural stiffness leads however to a reduction of the deformation capacity at failure [14,15]. As Fig. 2b shows, the strength and deformation capacities are also dependent on the level of load at the moment of strengthening [16]. Strengthening for levels of load similar to the strength of the unstrengthened slab $\left(V_{R}\right)$ leads to a poor efficiency of the system (low increase of strength), whereas the efficiency in terms of strength is larger for strengthening occurring at low load levels $\left(V_{R, s t(1)}>V_{R, s t(2)}\right.$ in Fig. 2b).

This behaviour (increasing shear strength but decreasing deformation capacity of the strengthened slabs) can be considered as peculiar to this type of strengthening, whereas other approaches for strengthening (such as post-installing shear reinforcement) are aimed at increasing both the failure load and deformation capacity [16-18]. Despite this physical reality, most design approaches based on empirical formulas do not acknowledge for the reduction of the deformation capacity and the influence of the level of load at the moment of strengthening, and may potentially lead to unsafe or unexpectedly brittle designs. In this paper, the topic of punching strengthening of flat slabs with glued FRP's is investigated on the basis of the mechanical model of the CSCT. Suitable load-rotation curves are developed and the approach is validated through comparisons to available test data from the literature. The mechanical model of the CSCT is finally used to investigate the influence of FRP strengthening on actual (continuous) flat slabs, where moment redistributions occur due to cracking and

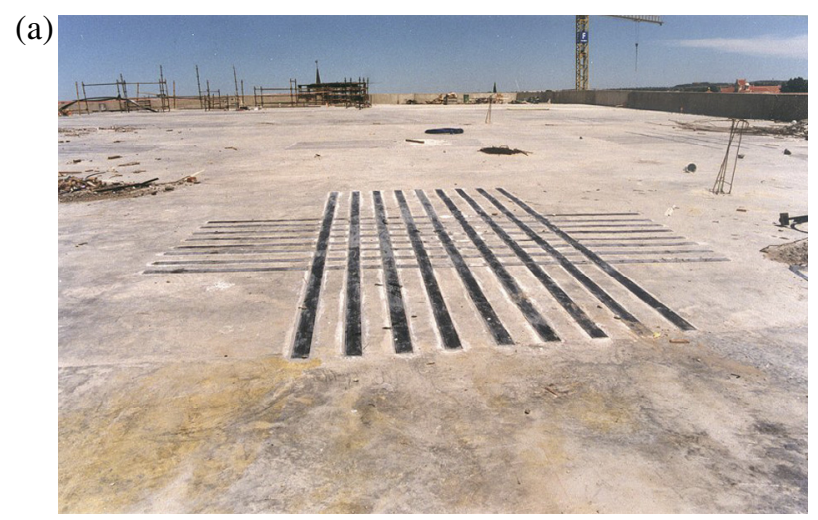

(b)

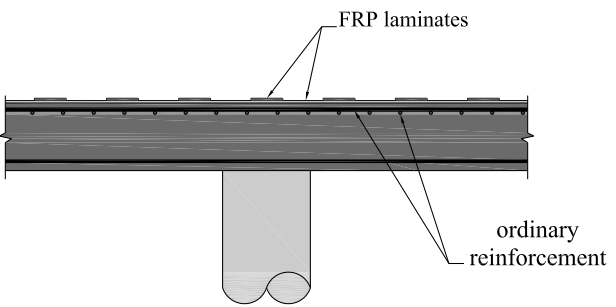

Fig. 1. (a) Practical application of bonded FRP's for slab strengthening (courtesy of VSL), and (b) cross-section of a strengthened slab.
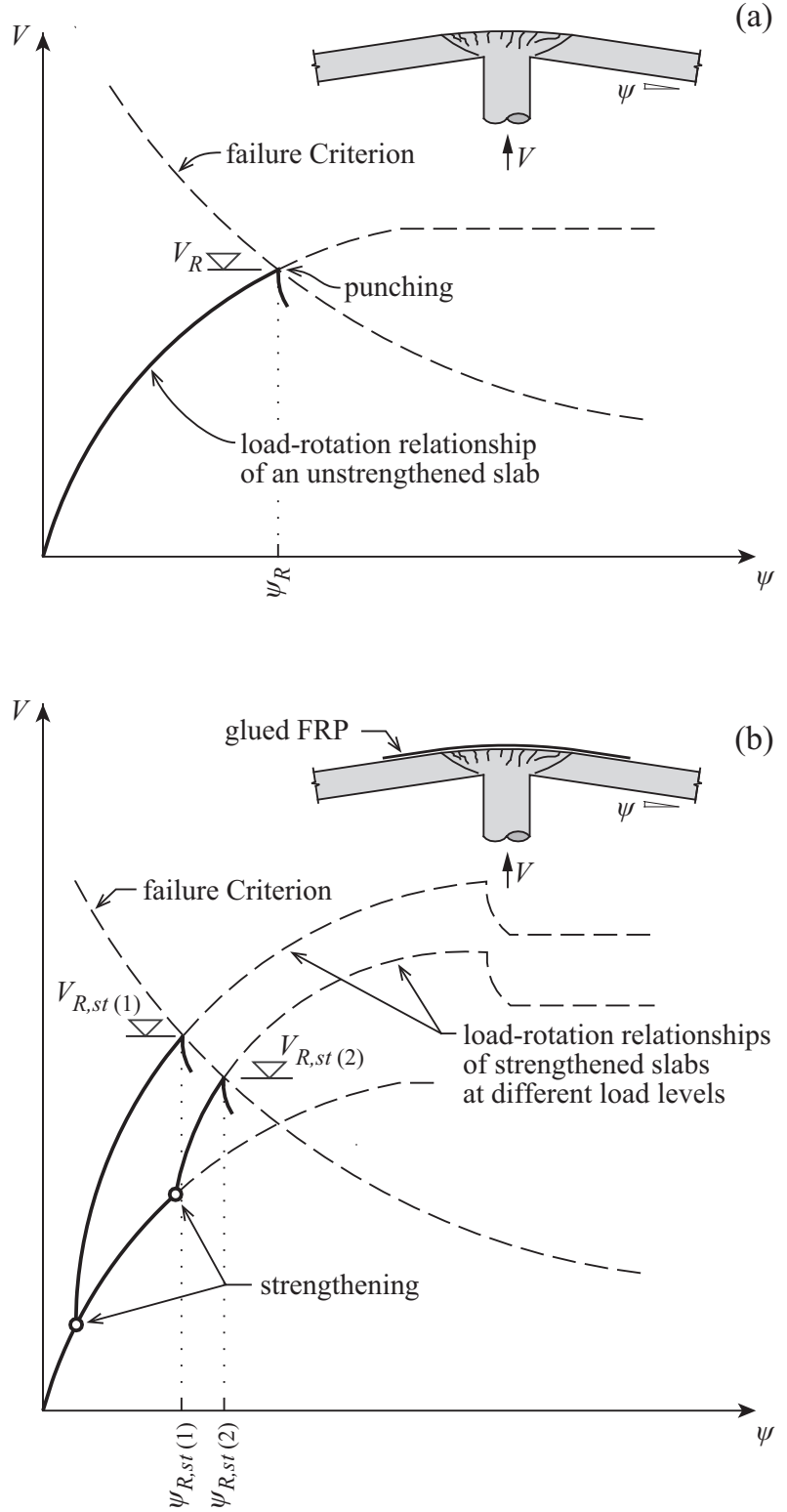

Fig. 2. Behaviour of flat slabs: (a) unstrengthened; and (b) strengthened at various load levels.

flexural reinforcement yielding. This investigation will focus on the punching strength of the connections strengthened using FRP's with sufficient bonded length, and other potential failure modes (such as debonding or laminate failure) will not be investigated.

\section{Mechanical behaviour of flat slabs strengthened with post- installed glued FRP strips}

In the following, the mechanical behaviour of concrete slabs strengthened with FRP's glued on the surface is investigated on the basis of the mechanical model of the CSCT. This approach is selected as it allows relating the shear force that can be carried by the concrete to the activation of the glued strengthening and available reinforcement.

\subsection{Failure criterion of concrete according to the CSCT}

The fundamentals of the CSCT to slabs without transverse reinforcement have been presented in detail elsewhere [14]. According 
to this theory, the punching shear strength of a flat slab depends on the opening and roughness of a critical shear crack that develops through the inclined compression strut carrying shear, refer to Fig. 3. The opening of the critical shear crack $(w)$ can be related to the rotation $(\psi)$ of the slab around the slab-column connection times the effective depth of the member: $w \propto \psi \cdot d_{s}$ (where $d_{s}$ refers to the effective depth of the slab measured between the bottom compressed face and the centroid of the top longitudinal reinforcement bars). According to this hypothesis, and by considering the roughness of the failure surface proportional to the maximum aggregate size, Muttoni [14] proposed the following failure criterion to calculate the shear strength of flat slabs:

$V_{R}=\frac{3}{4} \frac{b_{0} \cdot d_{s} \cdot \sqrt{f_{c}}}{1+15 \cdot \frac{\psi \cdot d_{s}}{d_{g 0}+d_{g}}}$

where $\psi$ is the slab rotation at failure, $b_{0}$ is the length of the control perimeter at a distance equal to $d_{s} / 2$ from the edge of the supported area, $f_{c}$ is the compressive strength of the concrete in (MPa), $d_{g}$ is the maximum aggregate size and $d_{g 0}$ is a reference aggregate size of $16 \mathrm{~mm}$. In Eq. (1), the effect of the slab slenderness and of the amount, stiffness and yield stress of the reinforcement is taken into account in the slab rotation $\psi$. Size effect is accounted by the parameter $d_{s}$ in the denominator of Eq. (1).

In case a slab presents a number of layers of reinforcement (as for slabs strengthened in flexure), the effective depth $d_{s}$ of Eq. (1) is to be replaced by an average effective depth $\left(d_{e q}\right)$, which also modifies the length of the control perimeter ( $b_{e q}$ at a distance of $d_{e q} / 2$ from the edge of the supported area):

$V_{R}=\frac{3}{4} \frac{b_{e q} \cdot d_{e q} \cdot \sqrt{f_{c}}}{1+15 \cdot \frac{\psi \cdot d_{e q}}{d_{g 0}+d_{g}}}$

For brittle failures in punching (critical failures with low rotation capacity), the flexural reinforcement remains mostly elastic. Thus, $d_{e q}$ can be calculated as an average of $d_{s}$ and the effective depth of the strengthening reinforcement $\left(d_{s t}\right)$, weighted upon the stiffness of each layer:

$d_{e q}=\frac{d_{s} \cdot a_{s} \cdot E_{s}+d_{s t} \cdot a_{s t} \cdot E_{s t}}{a_{s} \cdot E_{s}+a_{s t} \cdot E_{s t}}=d_{s} \cdot \frac{1+\frac{\rho_{s t}}{\rho_{s}} \cdot \frac{E_{s t}}{E_{s}} \cdot\left(\frac{d_{s t}}{d_{s}}\right)^{2}}{1+\frac{\rho_{s t}}{\rho_{s}} \cdot \frac{E_{s t}}{E_{s}} \cdot\left(\frac{d_{s t}}{d_{s}}\right)}$

where $a_{s}$ is the cross sectional area of the longitudinal reinforcement per unit width, $a_{s t}$ is the cross sectional area of the strengthening reinforcement per unit width, $\rho_{s t}$ is the strengthening

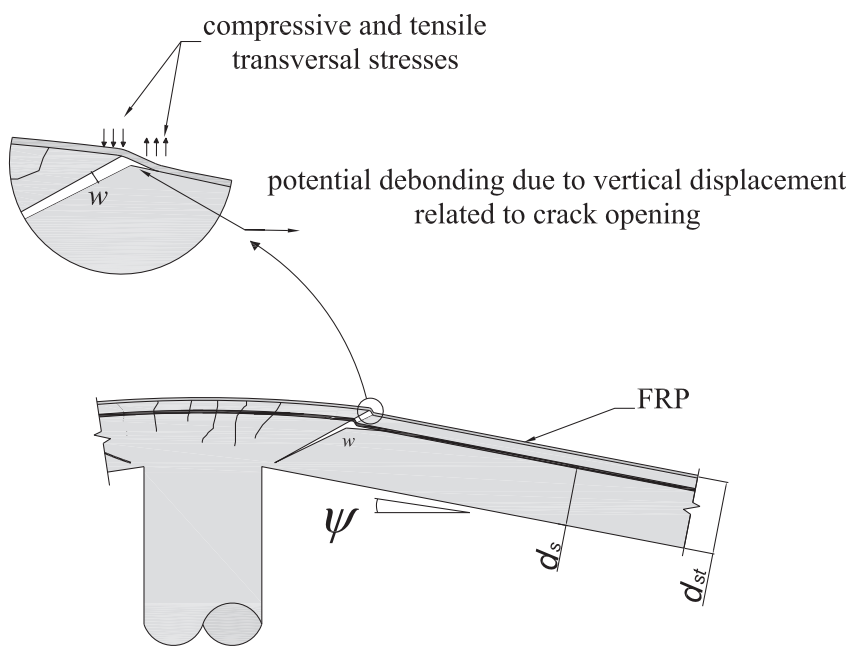

Fig. 3. FRP debonding in the vicinity of the critical shear crack. reinforcement ratio $\left(=a_{s t} / d_{s t}\right) ; \rho_{s}$ is the ordinary reinforcement ratio $\left(=a_{s} / d_{s}\right) ; E_{s t}$ and $E_{s}$ are the modulus of elasticity of the strengthening reinforcement and of the ordinary reinforcement bars. It can be noted that Eq. (3) is only applicable when the strengthening reinforcement crosses the critical shear crack $r_{0}$ from the column face (refer to radial FRP in Fig. 5), otherwise $d_{s}$ applies.

\subsection{Load-rotation behaviour of isolated slab tests specimens}

In order to calculate the punching shear capacity of a slab using Eq. (2), it is necessary to determine the load-rotation $(V-\psi)$ relationship of the slab, refer to Fig. 1a. In the following this will be done by considering that no FRP debonding failure happens. Despite the fact that it will not be investigated hereafter, considering bond failures of FRP's is however possible as the model by Muttoni [14] allows considering the gradient of moments and strains, thus enabling the implementation of FRP bond failure models from existing works $[13,19,20]$ to two way slabs. In [14], it was shown that the load-rotation relationship can be suitably estimated for reinforced concrete slabs considering a quadrilinear moment-curvature $(M-\chi)$ relationship for the cross-sections (Fig. 4, case (a)).

When considering slabs strengthened with glued FRP strips, the $M-\chi$ law has to be modified to suitably account for the contribution of the FRP strips. This leads to a larger number of potential regimes and cases, refer to Fig. 4. The various regimes show a linear behaviour that can be characterized as follows:

- $E I_{0}$ - stiffness before cracking (stiffness of strengthening can be neglected).

- $E I_{1}$ - stiffness of the cracked unstrengthened section.

- $E I_{2}$ - stiffness of the cracked strengthened section.

- $\mathrm{EI}_{3}$ - stiffness of the strengthened section after yielding of the ordinary reinforcement bars.

Such moment-curvature laws can also take account of the construction sequence (that is, the load level at which the strengthening is performed) leading to three different cases (Fig. 4, cases (b-d)). Appendix B of this paper describes a possible approach to obtain suitable moment-curvature relationships for reinforced concrete sections reinforced with glued FRP strips.

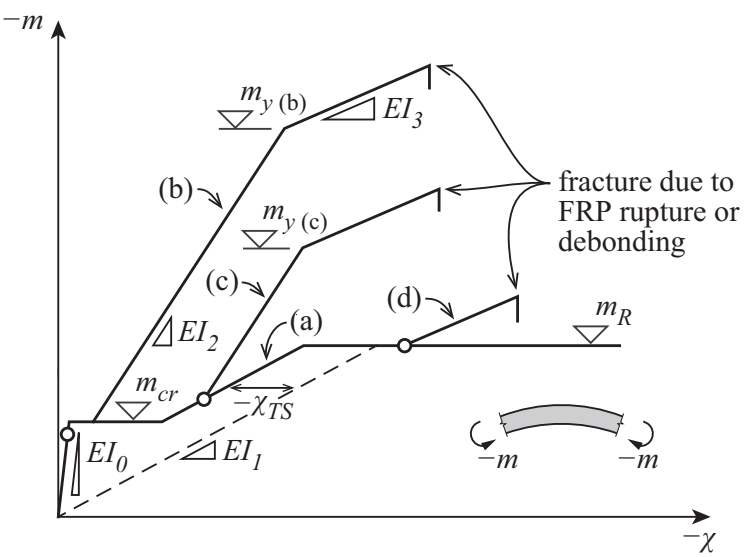

(a) unstrengthened slab

(b) strengthening before section cracking

(c) strengthening before reinforcement yielding

(d) strengthening after reinforcement yielding

Fig. 4. Moment curvature relationship of unstrengthened and strengthened RC sections. 

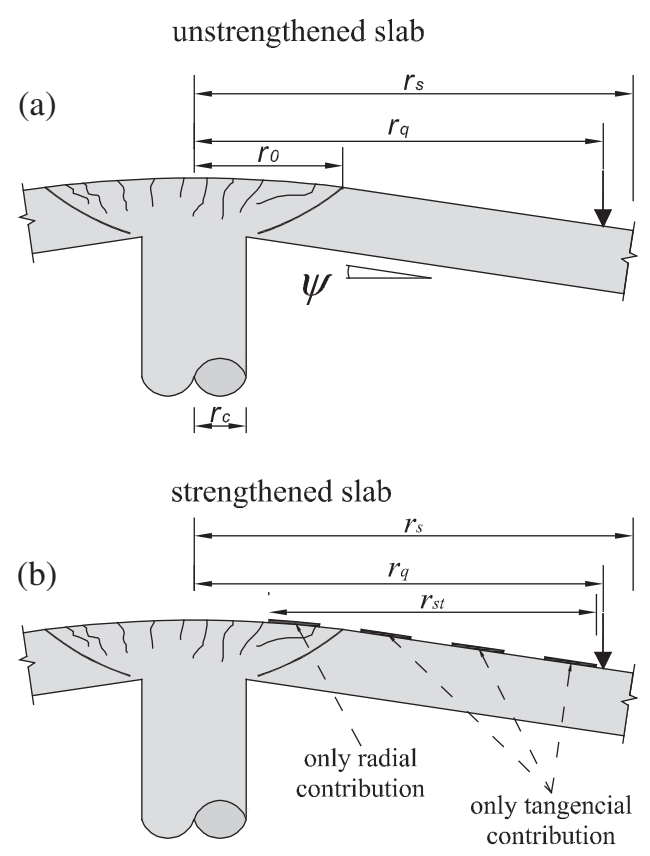

(c)

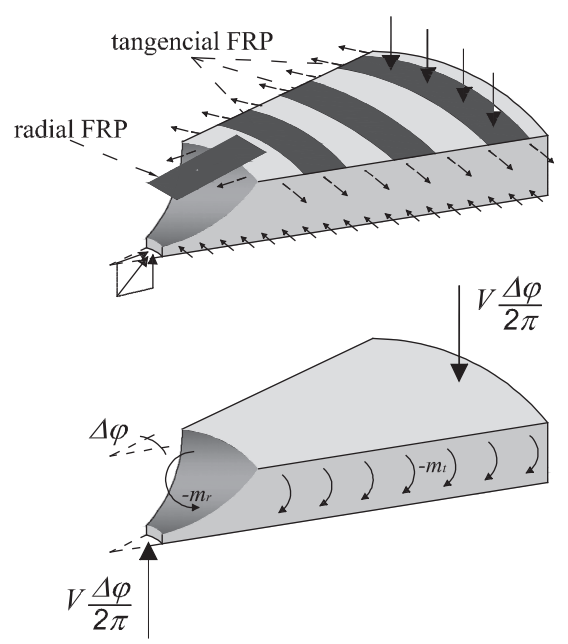

Fig. 5. Assumed behaviour for axisymmetric slab: (a) unstrengthened slab; (b) strengthened slab; (c) forces in concrete and in reinforcement; and (d) internal forces acting on slab sector.

On the basis of given sectional moment-curvature, the loadrotation relationship of a slab $(V-\psi)$ can be determined for an axis-symmetric slab portion by accounting for equilibrium and kinematical conditions [14]. To do so, it is assumed that outside the critical shear crack (Fig. 5), the slab portion deforms following a conical shape with a constant slab rotation $(\psi)$, whereas it deforms following a spherical shape within this region. The equilibrium conditions of the slab portion shown in Fig. 5d (conical region) lead to the following expression:

$V \cdot \frac{\Delta \varphi}{2 \pi} \cdot\left(r_{q}-r_{c}\right)=-m_{r} \cdot \Delta \varphi \cdot r_{0}-\Delta \varphi \cdot \int_{r_{0}}^{r_{s}} m_{t} d r$

where $m_{r}$ is the radial moment at $r_{0}$ (computed using the $M-\chi$ relationships, hogging moment assumed to be negative) with $\chi_{r}=-\frac{\psi}{r_{0}}$. The tangential moment $m_{t}$ along the distance $r_{s}-r_{0}$ can also be determined using the corresponding $M-\chi$ relationships as a function of $\chi_{t}=-\psi / r$. For reinforced slabs associated to quadri-linear moment-curvature relationships, an analytical solution to Eq. (4) can be found [13]. For the very general case of a slab strengthened with FRP strips at a given load level, a numerical integration of Eq. (4) is more suitable in order to determine the shear force developed for a given level of rotation. This approach, thoroughly described in Appendix $C$ of this paper, will be followed hereafter.

\section{Analisis of available tests results on isolated slab specimens}

\subsection{Description of the selected test data}

Several experimental programmes regarding the behaviour of strengthened flat slabs using bonded FRP strips have been carried out in the last years. In the following, test results on symmetrical isolated slab specimens that reported all necessary mechanical and geometrical properties to be compared to the previous mechanical model and with an effective depth $d_{s}$ larger than $80 \mathrm{~mm}$ (to account for realistic dimensions in practice) were selected $[1,8,12]$. Some other works $[2-7,9-11]$ were not considered as there was no information on the maximum aggregate size or the slabs were relatively thin. Table 1 presents the main characteristics of the tested slab specimens and the experimental and predicted load capacity of each specimen. These series are briefly described below.

Abdullah et al. [12] tested four slabs measuring $1800 \times$ $1800 \times 150 \mathrm{~mm}$ together with a reference specimen used for comparisons. One of the specimens was strengthened with nonprestressed CFRP laminates, whereas the other three had prestressed laminates. It was shown that the load capacity of the non-prestressed specimen increased considerably up to $43 \%$. The three specimens with prestressed laminates failed due to debonding and will not be considered in this investigation. Suter and Moreillon [8] tested four FRP strengthened slab specimens, along with a control specimen, measuring $2400 \times 2400 \times 200 \mathrm{~mm}$. The aim of this series was to investigate on the serviceability behaviour and increase of strength resulting from different strengthening materials, such as FRP's (carbon, glass and aramid) laminates or tissues. According to the authors [8], the results showed that the increase on strength is dependent on the strengthening type and layout, reaching a maximum of approximately $20 \%$. Wang and Tan [1] tested four slab specimens, from which one was a reference slab. The specimens measured $1750 \times 1750 \times 120 \mathrm{~mm}$. The adopted strengthening consisted of glued CFRP tissues. It was found that the strengthening slabs presented almost no improvement in the load capacity, but a stiffer behaviour was recorded. It can be noted that, in some cases, the failure of the slabs was accompanied by debonding of the FRP's. These debonding phenomena are probably related to the relative vertical displacement associated to the conical failure surface during the punching failure process (Fig. 3).

The efficiency as strengthening of the glued FRP's reported in the previous works is quite different (refer to Table 1 ). This seems to be related to the ratio between the flexural stiffness of the unstrengthened slab and the strengthened one. For instance, Wang and Tan's [1] slabs had a relatively high reinforcement ratio of ordinary steel (corresponding to a stiff and brittle behaviour according to Fig. 2). The strengthening, on the contrary, was constituted by thin tissues, with relatively low axial stiffness. The overall influence of the strengthening on the flexural behaviour was thus limited (limited increase on the stiffness of the slab) and the corresponding increase on the punching failure load was therefore limited. This observed behaviour is in agreement to the CSCT approach.

\subsection{Analysis of test data using the CSCT}

The use and application of the CSCT to several cases has already been described in detail in previous works (punching with and 
Table 1

Tests specimens and comparison with the CSCT.

\begin{tabular}{|c|c|c|c|c|c|c|c|c|c|c|c|c|}
\hline & Specimen & $\begin{array}{l}d_{s} \\
(\mathrm{~mm})\end{array}$ & $\begin{array}{l}f_{c} \\
(\mathrm{MPa})\end{array}$ & $\begin{array}{l}d_{g} \\
(\mathrm{~mm})\end{array}$ & $\begin{array}{l}f_{y} \\
(\mathrm{MPa})\end{array}$ & $\begin{array}{l}\rho_{s} \\
(\%)\end{array}$ & FRP properties & $\begin{array}{l}d_{e q} \\
(\mathrm{~mm})\end{array}$ & $\begin{array}{l}V_{R, \text { test }} \\
(\mathrm{kN})\end{array}$ & $\begin{array}{l}\bar{v}=V_{R, \text { test }} /\left(b_{0} d_{s}\right. \\
\left.\sqrt{f_{c}}\right)\end{array}$ & $\frac{\bar{v}}{\bar{v}_{\text {ref }}}$ & $\begin{array}{l}V_{R, \text { test }} / \\
V_{R, \text { calc }} \\
\end{array}$ \\
\hline \multirow[t]{3}{*}{ Wang and Tan [1] } & RC-0 & 95 & $26.1^{\mathrm{a}}$ & 10 & 518 & 1.19 & - & - & 242 & 0.56 & 1.00 & 1.14 \\
\hline & CS-1 & & $23.0^{\mathrm{a}}$ & & & & $\begin{array}{l}1 \text { Carbon FRP tissues in each direction } \\
\text { along the complete surface with } \\
0.160 \mathrm{~mm} \text { thick; } E_{s t}=235 \mathrm{GPa} \\
f_{\text {stu }}=3550 \mathrm{MPa}\end{array}$ & 99 & 242 & 0.59 & 1.05 & 1.15 \\
\hline & CS-2 & & $22.2^{\mathrm{a}}$ & & & & $\begin{array}{l}2 \text { Superposed carbon FRP tissues in } \\
\text { each direction along the complete } \\
\text { surface with } 0.160 \mathrm{~mm} \text { thick; } \\
E_{s t}=235 \mathrm{GPa} ; f_{\text {stu }}=3550 \mathrm{MPa}\end{array}$ & 103 & 244 & 0.61 & 1.09 & 1.09 \\
\hline \multirow{5}{*}{$\begin{array}{l}\text { Suter and Mureillon } \\
\text { [8] }\end{array}$} & DA-01 & 170 & 36 & $16^{\mathrm{c}}$ & $500^{\mathrm{b}}$ & 0.31 & - & - & 470 & 0.31 & 1.00 & d \\
\hline & DA-04 & & 37 & & & & $\begin{array}{l}\text { Carbon FRP laminates measuring } \\
80 \times 1.2 \mathrm{~mm} ; E_{s t}=164 \mathrm{GPa} \\
f_{\text {stu }}=2800 \mathrm{MPa}\end{array}$ & 190 & 495 & 0.32 & 1.03 & 1.00 \\
\hline & DA-06 & & 39 & & & & $\begin{array}{l}2 \text { Superposed glass FRP tissues in } \\
\text { each direction with a cross section of } \\
670 \times 0.308 \mathrm{~mm} ; E_{s t}=73 \mathrm{GPa} \text {; } \\
f_{\text {stu }}=3400 \mathrm{MPa}\end{array}$ & 179 & 491 & 0.31 & 1.00 & 1.05 \\
\hline & DA-07 & & 45 & & & & $\begin{array}{l}3 \text { Superposed aramid FRP laminates } \\
\text { in each direction with a cross section } \\
\text { of } 300 \times 0.200 \mathrm{~mm} ; E_{\text {st }}=120 \mathrm{GPa} \text {; } \\
f_{\text {stu }}=2900 \mathrm{MPa}\end{array}$ & 178 & 514 & 0.30 & 0.97 & 1.12 \\
\hline & DA-08 & & 45 & & & & $\begin{array}{l}3 \text { Superposed carbon FRP laminates } \\
\text { in each direction with a cross section } \\
\text { of } 300 \times 0.176 \mathrm{~mm} ; E_{s t}=240 \mathrm{GPa} \text {; } \\
f_{\text {stu }}=3800 \mathrm{MPa}\end{array}$ & 182 & 566 & 0.33 & 1.06 & 1.08 \\
\hline \multirow[t]{4}{*}{ Abdullah et al. [12] } & $\mathrm{RS}_{0}$ & 118 & 35.5 & 10 & 570 & 0.43 & - & - & 284 & 0.30 & 1.00 & 1.01 \\
\hline & $\mathrm{RS}-\mathrm{F}_{0}$ & 118 & 35.5 & 10 & 570 & 0.43 & $\begin{array}{l}\text { Carbon FRP laminates with a cross } \\
\text { section of } 120 \times 1.2 \mathrm{~mm} \text {; } \\
E_{s t}=172 \mathrm{GPa} ; f_{s t u}=2970 \mathrm{MPa}\end{array}$ & 139 & 405 & 0.42 & 1.40 & 1.07 \\
\hline & & & & & & & & & & & Average & 1.08 \\
\hline & & & & & & & & & & & $\mathrm{COV}$ & 0.05 \\
\hline
\end{tabular}

\footnotetext{
a Computed as $80 \%$ of the cubic compressive strength.

b Authors only reported a characteristic yield strength.

c Private communication by the author.

d The reference specimen had a flexural failure mode with hardening, and thus it was not considered. The control perimeter is calculated at a distance $d_{\text {eq }} / 2$ form the edge of the column according to MC2010 [31].
}

without shear reinforcement, fibres, prestressing and others $[14,16,21-25])$. In this paper, focus is given to its application to the case of strengthened slabs using bonded FRP strips. To that aim, some specific considerations are needed in the computation of the bending strength and in the layout and behaviour of the used FRP's. According to Fig. 5b, bonded FRP's positioned outside $r_{0}$, are only considered as contributing to the tangential moment $m_{t}$, while bonded FRP's positioned inside $r_{0}$ are only considered as contributing to the radial moment $m_{r}$ (as long as they develop over the critical shear crack, and have and sufficient bonded anchorage length).

Fig. 6 presents the experimental and computed load-rotation relationships for the tests by Abdullah et al. [12], where good agreement between the theory and the actual behaviour can be observed. The highest increase on the punching strength due to the FRP strengthening was obtained by Abdullah et al. [12]. This is explained by the fact that the unstrengthened test failed due to punching after extensive rebar yielding and, thus, the effect of the strengthening on the flexural behaviour is quite significant (leading to a high increase on the punching load and a large reduction of the deformation capacity). More details on the accuracy of the predictions are presented in Table 1. For the other tests, failure of the control specimens occurred with limited rebar yielding and thus the influence of the FRP strengthening on the punching strength was more limited (due to a less significant increase on the flexural stiffness).

From the observation of the results (Table 1) it can be concluded that the CSCT provides good agreement with the test results and so it can be used to predict the load capacity of FRP flexural strengthened slab specimens subjected to a concentrated loading. The average relation, between the measured and the computed capacity is of 1.08 with a very low value of the Coefficient of Variation (5\%). This low value of the Coefficient of Variation may also be related to the limited amount of available tests that were used in the analysis.

\section{Influence of the strengthening and slab reinforcement distribution}

This section takes advantage of the physical model of the CSCT presented before to investigate on the efficiency of FRP strengthening against punching shear. This is performed with reference to an example of a slab whose geometry is given in Fig. 7b. The geometry of the slab (span length $L=6.00 \mathrm{~m}$ and slab thickness of $250 \mathrm{~mm}$ ) is selected in order to be identical to other available examples on realistic flat slabs [21]. The example focuses first on the behaviour of an isolated specimen of an inner slab-column connection (Fig. 7a) and will later be completed with the complete flat slab behaviour (Fig. 7b, accounting for the influence of the top and bottom reinforcement).

Concrete is considered with an average compressive strength of $f_{c}=40 \mathrm{MPa}$, and reinforcing bars with an average yield strength of $f_{y}=550 \mathrm{MPa}$ and a modulus of elasticity $E_{s}=205 \mathrm{GPa}$ (all analyses were performed considering average material properties with no partial safety factors in-built). The considered strengthening 
consists of CFRP laminates measuring $120 \times 1.4 \mathrm{~mm}$, with a spacing of $170 \mathrm{~mm}$, a modulus of elasticity $E_{s t}=210 \mathrm{GPa}$ and a tensile strength of $2800 \mathrm{MPa}$.

\subsection{Parametric analysis}

The parametrical analysis considers two main parameters:

1. The amount of top and bottom flexural reinforcement in the slab (four different configurations: $\rho_{s, t o p}=0.30 \%$ with $\rho_{s, b o t}=$ $1.20 \% ; \quad \rho_{s, \text { top }}=0.75 \%$ with $\rho_{s, b o t}=0.70 \% ; \quad \rho_{s, \text { top }}=1.05 \%$ with $\rho_{s, \text { bot }}=0.42 \%$ and $\rho_{s, \text { top }}=1.25 \%$ with $\rho_{s, \text { bot }}=0.25 \%$ ), refer to Fig. 7;

2. The amount and layout of bonded FRP's laminates (Fig. 8).

The amount and layout of laminates was selected in order to simulate strengthening solutions commonly used in practice. The distribution of the reinforcement (top and bottom layers) was selected such that all the investigated unstrengthened slabs had approximately the same flexural capacity (yield plateau according to Eq. (4) and Appendix C). For each reinforcement configuration, the application of the six different amounts of strengthening are investigated, determining its influence on the behaviour and punching strength.

\subsection{Equivalent isolated slab specimens}

The punching shear strength is first investigated considering the region of the slab near the slab-column connection acting as an isolated specimen. To that purpose, it will be assumed that the line of contraflexure of bending moments is located at a distance equal to $0.22 \mathrm{~L}$ [14] from the centre of the column (location in agreement to an elastic moment field). As a consequence, only the top reinforcement influences the load-rotation curve (refer to Fig. 5). It is also assumed that the slab is strengthened from the beginning (unloaded and undeformed slab). The results, presented in terms of the punching strength $V_{R}$ and rotation capacity at failure $\psi_{R}$ are plotted in Fig. 9, as a function of the effective reinforcement ratio $\rho_{\text {tot }}$, defined in Eq. (5) to account for the bending stiffness of the slab:

$\rho_{t o t}=\rho_{s}+\rho_{s t} \cdot \frac{E_{s t}}{E_{s}} \cdot \frac{r_{s t}}{r_{s}}\left(\frac{d_{s t}}{d_{s}}\right)^{3}$

where $r_{s}$ and $r_{s t}$ are defined in Fig. 5b.

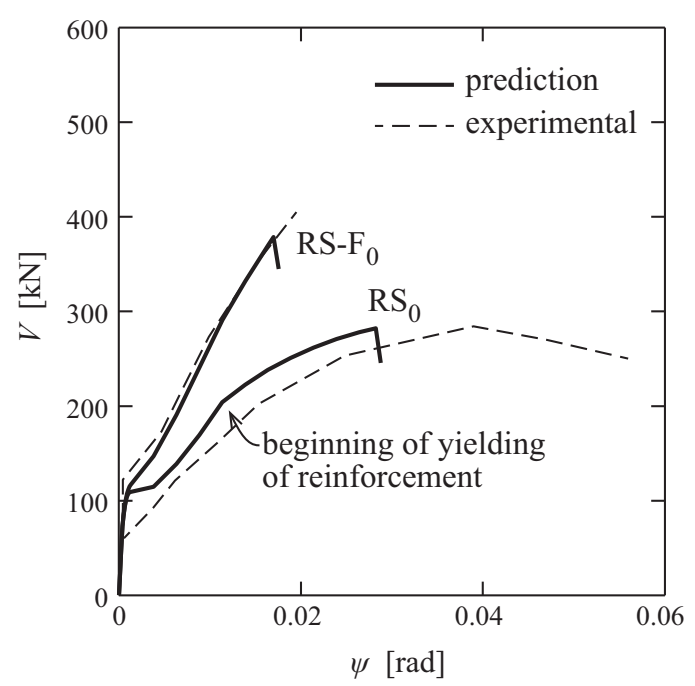

Fig. 6. Experimental and computed behaviour of tests by Abdullah et al. [12].
The results confirm that the increase of $\rho_{\text {tot }}$ leads to an increase of the punching strength (Fig. 9a) and to a decrease of the rotation capacity (Fig. 9b) and that flat slab strengthening is significantly more efficient in cases with low steel reinforcement ratio. Results from previous works show similar trends $[3-5,10]$. This is in agreement to the previously presented experimental data. The obtained results also show that the use of FRP's is more efficient in increasing the punching strength when compared to the increase in strength that would have been obtained using the same total reinforcement ratio of ordinary reinforcement (Fig. 9a). This is justified by the higher strength of FRP's compared to the reinforcement bars yield strength (not considered in Eq. (5), which accounts only for their stiffness) and also by the increased effective depth defined in Eq. (2).

\subsection{Behaviour of continuous flat slab}

In the previous section, the CSCT was applied to isolated slab specimens. However, the actual layout of reinforcement in a slab may have a considerable influence on the flexural behaviour of a slab and thus on its punching strength $[26,27]$. In a recent work [28], the physical model of the CSCT was used in order to predict the punching strength of three tested slabs with restrained edge rotations and different top and bottom reinforcement ratios [29] (following the approach described in Appendix C). It was shown that the CSCT, considering moment redistribution, provides good agreement with the tests results regarding both the punching strength and the load-deformation capacity behaviour. Moment redistribution allows additional activation of sagging bending reinforcement after cracking and/or yielding of hogging reinforcement. This moment redistribution stiffens the load-rotation response and thus reduces crack widths in the shear critical region, eventually increasing punching shear strength [28]. Therefore, the punching shear strength according to the CSCT considers all these parameters. On the contrary, approaches based on empirical formulas that do not allow taking into account the bottom reinforcement of the slab at mid-span (such as Eurocode 2 [30]) provided potentially too conservative results for slabs with low top reinforcement ratios over the column.

In Fig. 10, the response of the isolated slabs (Fig. 10a) and that of a continuous slab (Fig. 10b) are compared for the case with $\rho_{s, \text { top }}=1.05 \%$ and considering the various strengthening amounts (Fig. 8). In the presented cases, the punching strength of the continuous flat slabs is always higher than the one of an equivalent isolated specimen (specimen with $r_{s}=0.22 \mathrm{~L}$ subjected only to hogging moments). For each case, three failure criteria are considered, corresponding each to different square column sizes $(260 \mathrm{~mm}$, $350 \mathrm{~mm}$ and $450 \mathrm{~mm}$ ). The strength increase with respect to that of the isolated specimen is associated to the stiffer behaviour of the continuous slab and is particularly noticeable for the unstrengthened slab and for the larger column sizes. Fig. 11 shows the results in terms of punching strength and rotation capacity of the investigated continuous slabs. Qualitatively, the results are similar to those of the previous section (Fig. 9). Nevertheless, a detailed observation of the results show that the efficiency of the strengthening in the continuous slab is not as significant as in the isolated specimens, since the punching strength increases at a slower rate than for the isolated specimens.

This, as previously explained, is justified by the stiffer behaviour of the continuous flat slabs, which is associated to low deformation levels at failures and, consequently, to the development of low stresses in the FRP's. For example, in the slab with a top longitudinal reinforcement ratio of $0.75 \%$ and with the 7 strengthening laminates (Figs. 7 and 8), the punching shear increase is of only $20 \%$ for the continuous slab, whereas it was of $34 \%$ for isolated slab. 
(a)

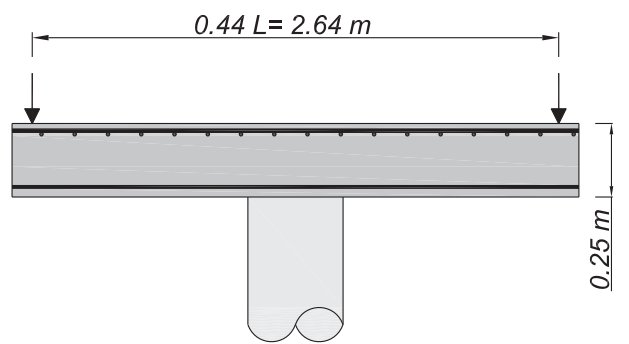

(b)

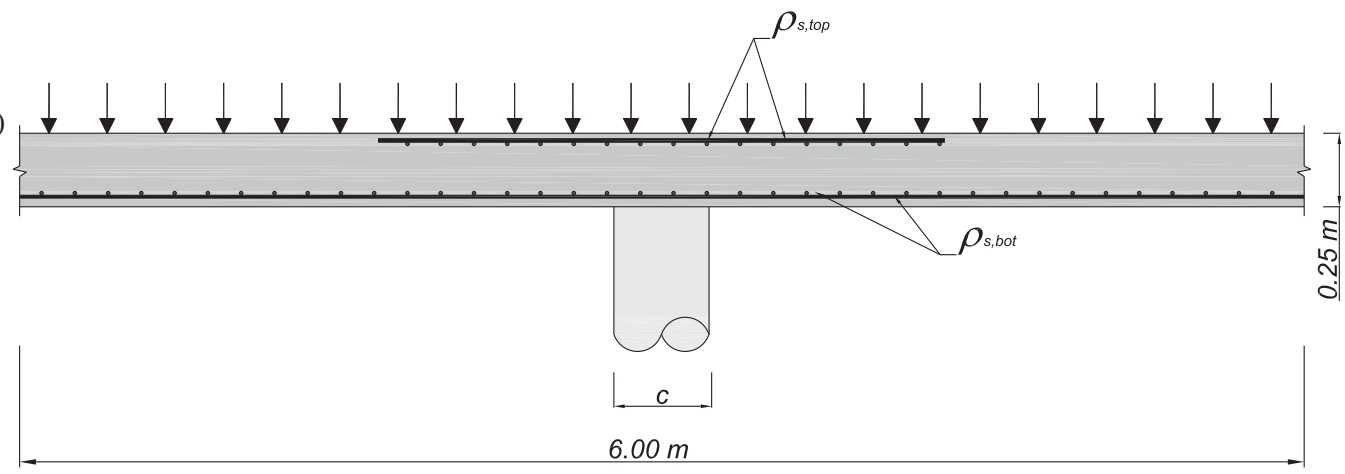

Fig. 7. Investigated members: (a) isolated specimen; and (b) continuous slab.

(a) strengthening with 2 laminates
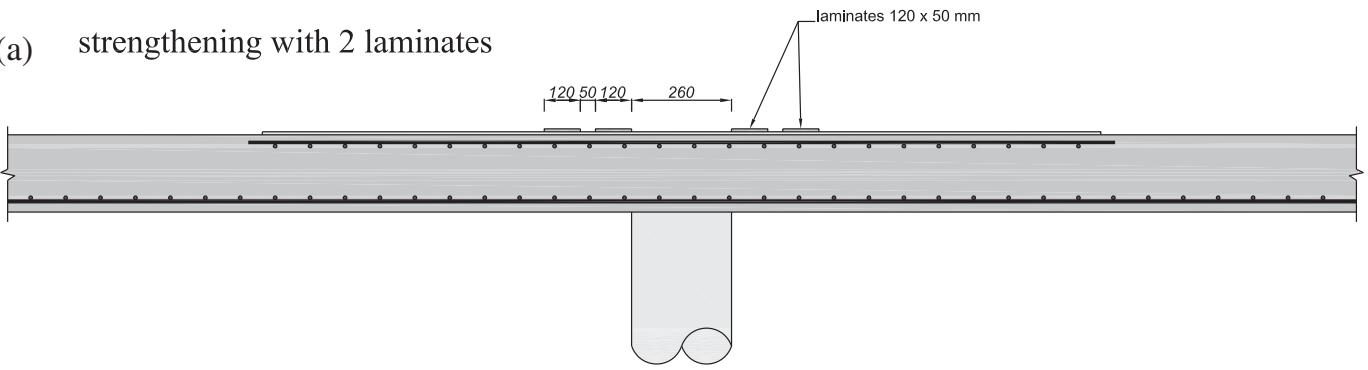

strengthening with 7 laminates

(b)

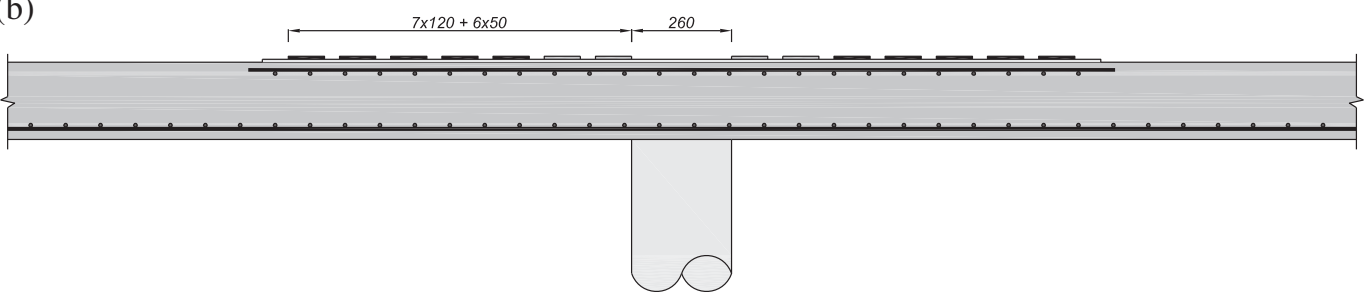

Fig. 8. Strengthening with FRP laminates, examples for: (a) two laminates and (b) seven laminates (dimensions in mm).

In Fig. $11 \mathrm{~b}$ it may also be noted that, in most cases, there is a slight increase on the rotation capacity between the unstrengthened and the strengthened specimens. This phenomenon is due to the fact that the failure criterion is not the same for all slabs, since $d_{e q}$ is increased by the strengthening. The results also show that the increase on the punching strength is not linearly proportional to the increase of the amount of strengthening material, and that the most efficient FRP strips are those located close to the column region. This is related to the strain developed in the FRP strengthening laminates (Eq. (6)), which depends on the slab rotation $\psi$ but also on the distance to the column $r$ [14]: $\varepsilon=\frac{\psi}{r} \cdot\left(d_{s t}-x\right)$

where $\varepsilon$ is the strain in the FRP laminates, $r$ is the radial distance from the column axis and $x$ is the depth of the compression zone.

Based on these results, it may be concluded that for slabs strengthened with low reinforcement ratios or large column sizes (Fig. 10), the FRP strips develop higher strains and are more efficient as strengthening technique. This positive aspect is nevertheless associated to a negative one, related to a higher risk of debonding of the FRP. In these cases, depending on the level of strain of 

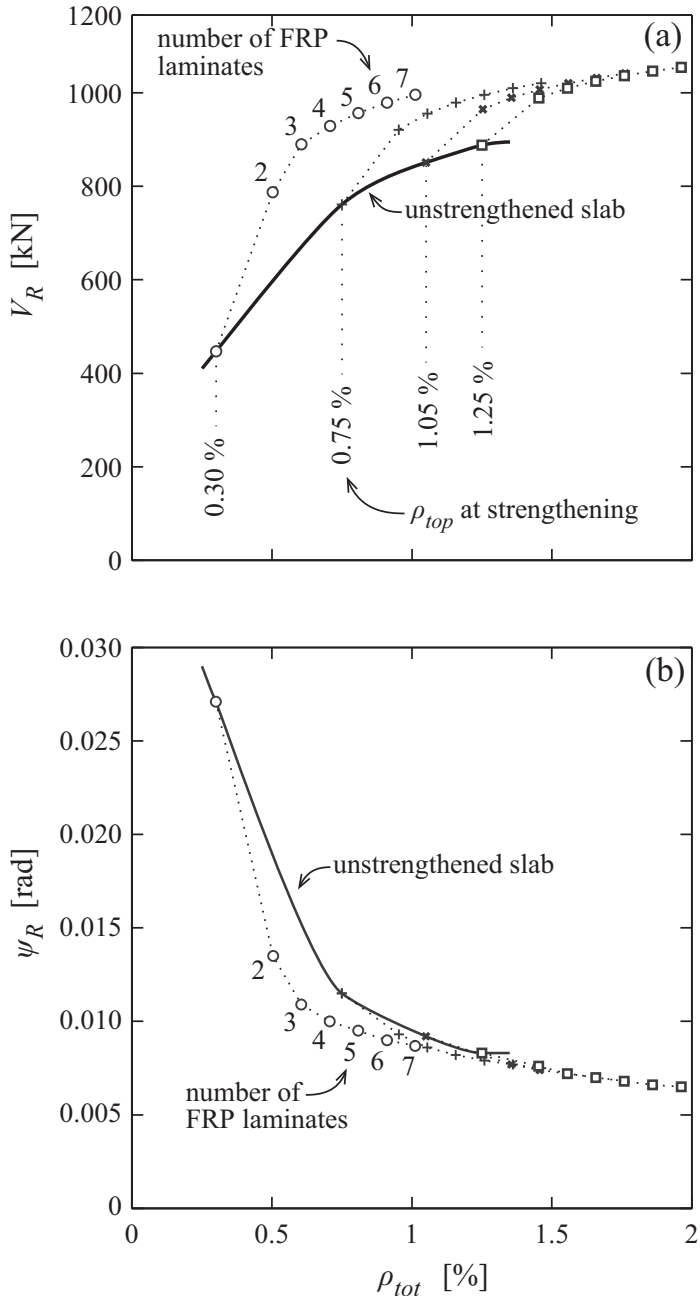

Fig. 9. (a) Punching shear strength and (b) rotation capacity as a function of $\rho_{\text {tot }}$ for the investigated isolated slab specimens, $c=260 \mathrm{~mm}$.

the FRP, adopting some special detailing measures may be necessary (such as anchorages for the FRP or mechanical connections).

It is pertinent to mention that the CSCT effectively allows accounting for moment transfer to columns due to unsymmetrical geometry or loading configuration. This influences the distribution of shear forces around the column as well as the load-rotation relationship of the slab. This topic can be consistently considered according to the CSCT [27] or to MC2010 [31].

\section{Influence of construction sequence on the punching strength and strengthening efficiency}

Another important issue that may have a considerable impact in the strengthening efficiency is the construction sequence. This influence is usually not considered in most empirical design equations calibrated with tests performed on slabs strengthened before loading. However, according to the physical model of the CSCT, neglecting the construction sequence on the strengthened slab may lead to an overestimate of its load capacity [16], refer to Fig. 2b.

Fig. 12 investigates the influence of the load level at which the strengthening is performed. The behaviour of the unstrengthened continuous slab $\left(\rho_{s, t o p}=0.75 \%, c=260 \mathrm{~mm}\right)$ is compared to those of two slabs strengthened at different load levels. The former, strengthened prior to the application of any load $\left(V_{s t}=0\right)$ and,
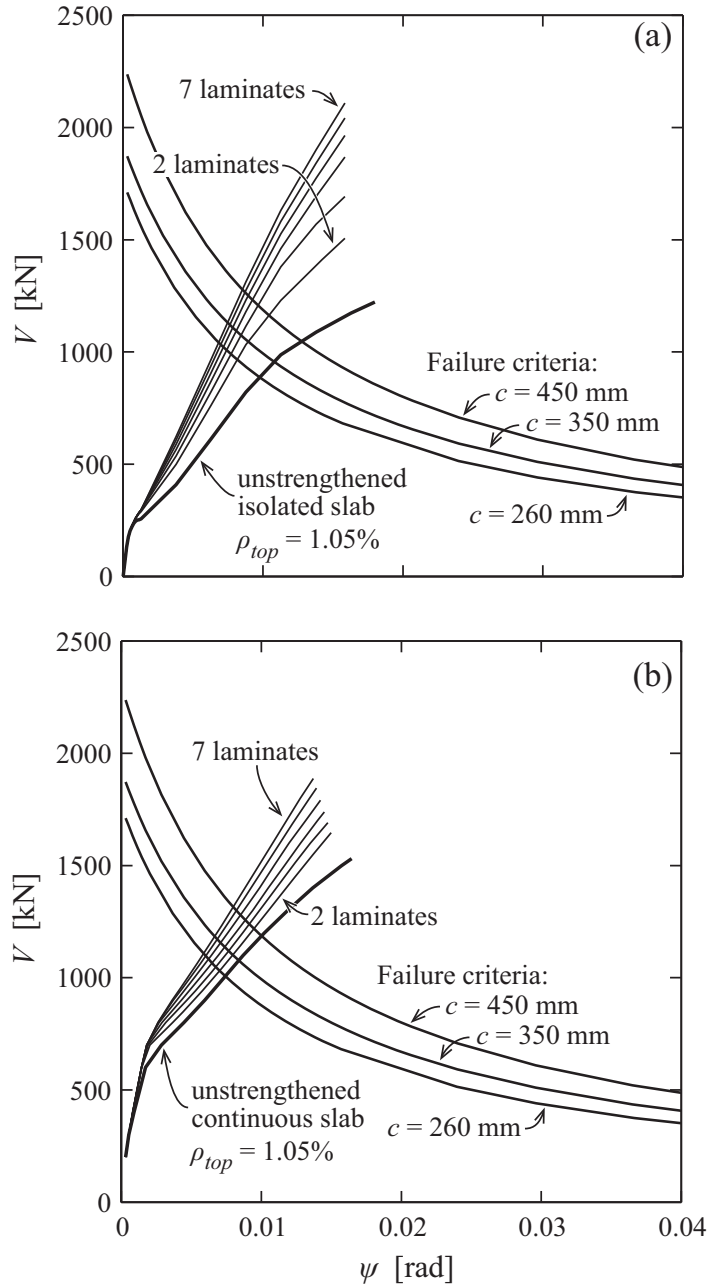

Fig. 10. Investigated slab behaviour and punching strength for (a) isolated and (b) continuous models.

the latter, strengthened at $85 \%$ of the unstrengthened slab punching strength. It may be observed that the load at which strengthening is performed has a strong influence on the response of the slab, both in terms of strength and deformation capacity. The increase on the punching capacity is $14 \%$ if the slab is strengthened prior to application of any load, but reduces to only $3.4 \%$ if the slab is strengthened at $85 \%$ of the unstrengthened punching load. This example clearly shows that the strengthening efficiency of nonprestressed FRP laminates can be considerably reduced when the slab is only capable of developing limited rotations after gluing of the FRP strips. A possible manner to improve the efficiency in these cases (provided that debonding issues are avoided) can be to prestress the FRP laminates $[8,9,12]$.

\section{Conclusions}

This paper investigates the efficiency of using bonded nonprestressed FRP's for strengthening of existing reinforced concrete flat slabs. The applicability of the Critical Shear Crack Theory (CSCT) was investigated, comparing it to available test data from different research works. This analysis is followed by a number of parametric analyses, both on isolated slab specimens (as the available test data) and continuous flat slabs (reproducing the behaviour of actual structures). The effect of the construction sequence was also investigated. The main conclusions of this investigation are: 

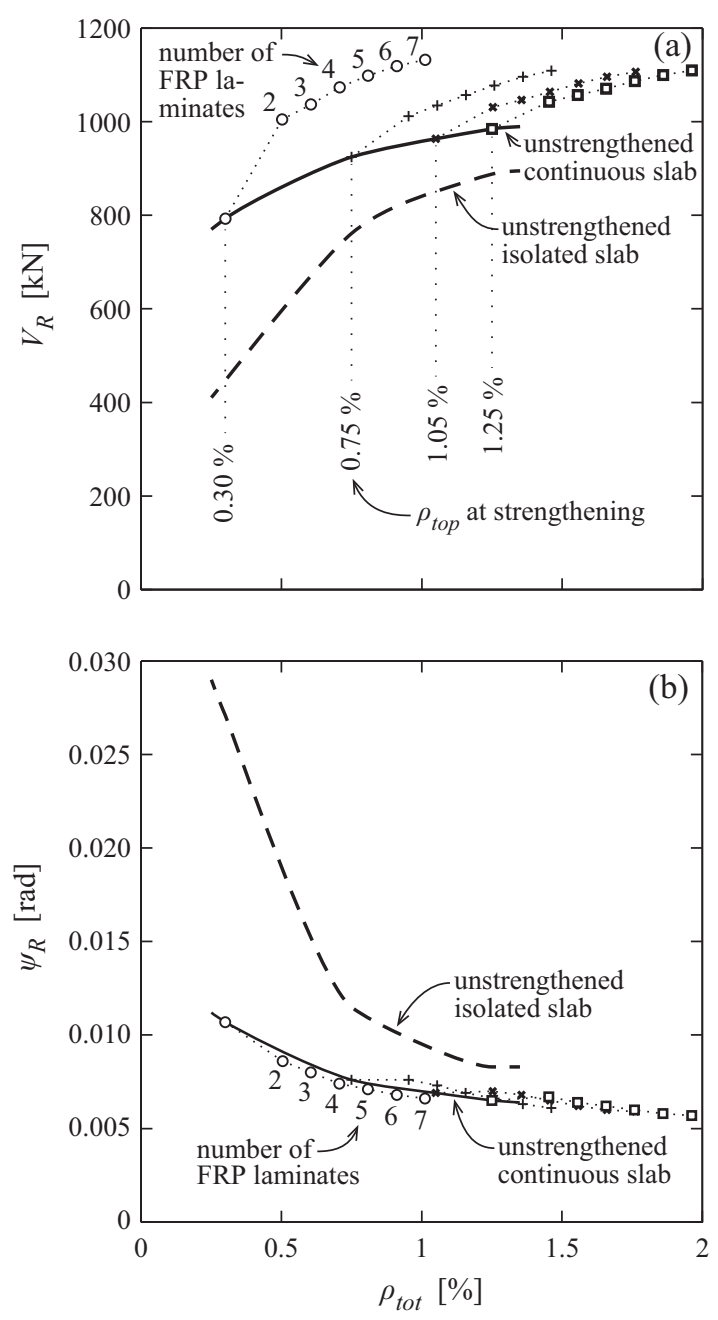

Fig. 11. (a) Punching shear strength and (b) rotation capacity as a function of $\rho_{\text {tot }}$ for the investigated continuous slab specimens, $c=260 \mathrm{~mm}$.

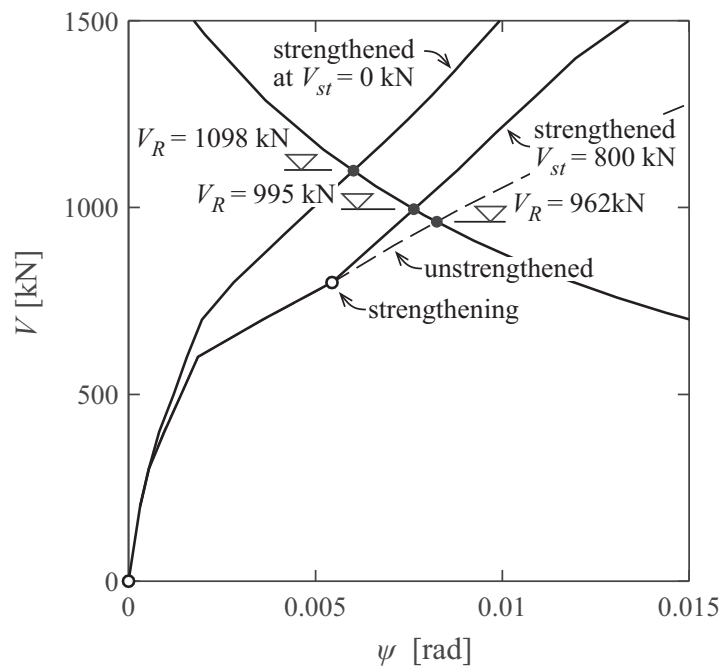

Fig. 12. Influence of the load at strengthening - continuous model, $\rho_{\text {top }}=0.75 \%$, $c=260 \mathrm{~mm}$, strengthening with 7 FRP laminates.

1. FRP's can be effectively used to strengthen existing flat slabs against punching shear failures. It should however be noted that although the strength may be increased, the deformation capacity of the slab decreases, which leads to potentially more brittle structures.
2. The mechanical model of the CSCT can be successfully applied in order to predict the punching strength of strengthened slabs using FRP's, taking into account its layout and considering the suitable moment-curvature relationships for the strengthened sections of the slab. The same suitability is expected in slabs strengthened with other flexural strengthening systems such as concrete topping layers and bonded steel plates.

3. Very good agreement is found when comparing the predictions of the CSCT to available test data (average ratio between the experimental and the computed punching strength of 1.08 with a Coefficient of Variation of 5\%).

4. According to the CSCT, the actual efficiency of the strengthening depends much on the deformations that can be developed by non-prestressed FRP strips during loading of the slab. This is highly influenced particularly by the redistribution of bending moments that can occur in a flat slab and by the load level at which strengthening is performed. These parameters are however not investigated by available testing (isolated specimens strengthened prior to the application of any load). Empirical formulas calibrated on the basis of these tests may thus lead to potentially unsafe estimates of the punching resistance of slabs strengthened with FRP strips.

5. The increase on punching strength due to strengthening is not linearly proportional to the amount of FRP laminates and depends on its location, with higher efficiencies for laminates glued near the slab-column connection.

6. The increase on punching strength due to strengthening is more pronounced in slabs with lower reinforcement ratio and larger column sizes. Thus, the use of bonded FRP's as a punching shear strengthening is more appropriate for these cases.

7. The efficiency of non-prestressed FRP laminates is lower in actual continuous flat slabs than in isolated specimens (usual test specimens). This is due to the stiffer behaviour of continuous flat slabs, associated to lower levels of deformation at failure.

\section{Acknowledgement}

The authors are appreciative to Dr. Lionel Moreillon, for is kindness in providing us information on the tests performed at EIA Fribourg [8].

\section{Appendix A}

Notation:

$A_{i} \quad$ area of a slab segment

$E_{c} \quad$ modulus of elasticity of the concrete

$E I_{i} \quad$ flexural stiffness of a section

$E_{s} \quad$ modulus of elasticity of longitudinal reinforcement

$E_{s t}$ modulus of elasticity of FRP

$L \quad$ span of slab

$M \quad$ applied moment in a section

$V \quad$ shear load applied to the slab

$V_{\text {exp }} \quad$ experimental failure load

$V_{R} \quad$ punching strength

$V_{R, s t} \quad$ punching strength of a strengthened slab

$V_{s t} \quad$ load level at strengthening

$a_{s} \quad$ cross-sectional area of the longitudinal reinforcement per unit width

$a_{s t} \quad$ cross-sectional area of the FRP strengthening per unit width

$b_{0} \quad$ length of the control perimeter at a distance equal to $d_{s} / 2$

$b_{\text {eq }} \quad$ length of the control perimeter at a distance equal to 
$d_{e q} / 2$

$d_{s}$ distance between the bottom compressed face and the centroid of the top longitudinal reinforcement bars

$d_{s t}$ distance between the bottom compressed face and the centroid of the FRP strengthening

$d_{e q} \quad$ equivalent effective depth

$d_{g} \quad$ maximum aggregate size

$d_{g 0} \quad$ is a reference size of aggregate which is $16 \mathrm{~mm}$

$f_{c} \quad$ average concrete compression strength on

$150 \times 300 \mathrm{~mm}$ cylinders

$f_{c t} \quad$ average concrete tensile strength

$f_{y} \quad$ yield strength of steel reinforcement

$h \quad$ slab depth

$m$

unitary bending moment (bending moment per unit width)

$m_{c r} \quad$ cracking moment per unit width

$m_{r} \quad$ radial moment per unit width

$m_{t} \quad$ tangential moment per unit width

$m_{R} \quad$ nominal moment capacity per unit width of the unstrengthened RC section

$m_{s t} \quad$ moment at strengthening

$m_{y} \quad$ moment corresponding to the yielding of the reinforcement bars in a strengthened section distributed load radial distance

radius of the critical shear crack location of the centre of gravity of the element radius of a circular column radius of the load introduction at the perimeter radius of circular isolated slab element distance where strengthening is distributed equivalent length of the control perimeter depth of the compression zone distance from extreme compression fibre to neutral axis of a section

crack opening

$\Delta_{r i} \quad$ length of a slab segment

$\Delta_{\varphi} \quad$ angle of a slab sector

$\beta \quad$ efficiency factor of bending reinforcement for stiffness calculation

$\delta \quad$ slab segment displacement

$\varepsilon \quad$ is the strain in the strengthening laminates

$\rho_{\text {tot }}$ total flexural reinforcement ratio

$\rho_{e q} \quad$ equivalent flexural reinforcement ratio

$\rho_{s} \quad$ average ratio of ordinary reinforcement

$\rho_{s t} \quad$ strengthening reinforcement ratio

$\rho_{s, t o p}$ slab top ordinary reinforcement ratio

$\rho_{s, b o t}$ slab bottom ordinary reinforcement ratio

$\chi$

$\chi_{1}$

$\chi_{c r}$

$\chi_{r}$

$\chi_{s t}$

$\chi_{T S}$

$\chi_{t}$

$\chi_{y}$

$\chi_{y, b}$

$\chi_{y, u}$

$\psi$ curvature of a section

curvature in stabilized cracking

curvature at cracking

radial curvature

curvature at strengthening

decrease in curvature due to tension stiffening tangential curvature

curvature corresponding to $m_{R}$

curvature corresponding to the yielding of the reinforcing bars of a strengthened section curvature corresponding to the yielding of the reinforcing bars of an unstrengthened section slab rotation

$\psi_{R} \quad$ slab rotation at failure

\section{Appendix B}

This appendix presents the elements necessary to compute the $M-\chi$ relationships presented in the paper. The relationships are characterized by stiffnesses $E I_{0}$ (stiffness before cracking, reinforcement stiffness can be neglected), $E I_{1}$ (stiffness of the cracked unstrengthened section), $E I_{2}$ (stiffness of the cracked strengthened section) and/or $\mathrm{EI}_{3}$ (stiffness of the strengthened section after yielding of the ordinary reinforcement bars), by moments and by curvatures. The terms before cracking are obtained neglecting the effect of the reinforcement (Fig. 5):

$E I_{0}=\frac{E_{c} \cdot h^{3}}{12}$

$m_{c r}=\frac{f_{c t} \cdot h^{2}}{6}$

$-\chi_{c r}=\frac{m_{c r}}{E I_{0}}$

After cracking, assuming linear-elastic behaviour of steel and concrete the following terms are computed:

$E I_{1}=\rho_{s} \cdot \beta \cdot E_{s} \cdot d_{s}^{3} \cdot\left(1-\frac{c_{1}}{d_{s}}\right) \cdot\left(1-\frac{c_{1}}{3 d_{s}}\right)$

$E I_{2}=\rho_{e q} \cdot \beta \cdot E_{s} \cdot d_{e q}^{3} \cdot\left(1-\frac{c_{2}}{d_{e q}}\right) \cdot\left(1-\frac{c_{2}}{3 d_{e q}}\right)$

$E I_{3}=\rho_{s t} \cdot \beta \cdot E_{s t} \cdot d_{s t}^{3} \cdot\left(1-\frac{c_{3}}{d_{s t}}\right) \cdot\left(1-\frac{c_{3}}{3 d_{s t}}\right)$

with:

$\rho_{e q}=\frac{a_{s}+a_{s t} \cdot \frac{E_{s t}}{E_{s}} \cdot \frac{d_{s t}}{d_{s}}}{d_{s}}=\rho_{s}+\rho_{s t} \cdot \frac{E_{s t}}{E_{s}} \cdot\left(\frac{d_{s t}}{d_{s}}\right)^{2}$

where the depth of the compressive zone is computed as:

$x_{e l, 1}=\rho_{s} \cdot \beta \cdot d_{s} \cdot\left(\sqrt{1+\frac{2 \cdot E_{c}}{\rho_{s} \cdot \beta \cdot E_{s}}}-1\right)$

$x_{e l, 2}=\rho_{e q} \cdot \beta \cdot d_{e q} \cdot\left(\sqrt{1+\frac{2 \cdot E_{c}}{\rho_{e q} \cdot \beta \cdot E_{s}}}-1\right)$

$x_{e l, 3}=\rho_{s t} \cdot \beta \cdot d_{s t} \cdot\left(\sqrt{1+\frac{2 \cdot E_{c}}{\rho_{s t} \cdot \beta \cdot E_{s t}}}-1\right)$

where $\beta$ is a factor accounting for the efficiency of an orthogonal reinforcement layout and the reduction in the ratio between the torsion and bending stiffness of the slab after cracking. It is assumed as 0.6 [14] and only affects the stiffness of the member and not its flexural strength. Considering a perfectly-plastic behaviour of the reinforcement after yielding, a rectangular stress block for concrete in the compression zone and neglecting the compression reinforcement, the unstrengthened section moment capacity may be computed as:

$m_{R}=\rho_{s} \cdot f_{y} \cdot d_{s}^{2} \cdot\left(1-\frac{\rho_{s} \cdot f_{y}}{2 \cdot f_{c}}\right)$

The tension stiffening effect can be taken as [13]:

$\chi_{T S}=\frac{f_{c t}}{\rho \cdot \beta \cdot E_{s}} \cdot \frac{1}{6 \cdot h}$ 
where in the place of $\rho$, the adequate value $\left(\rho_{s}\right.$ or $\left.\rho_{\text {eq }}\right)$ must be adopted in the corresponding $M-\chi$ relation. In the case where the strengthening occurs during the stabilized cracking regime, $\chi_{1}$ is given by:

$-\chi_{1}=\frac{m_{c r}}{E I_{1}}-\chi_{T S}$

while in the case where the strengthening occurs before the stabilized cracking regime, $\chi_{1}$ is given by:

$-\chi_{1}=\frac{m_{c r}}{E I_{2}}-\chi_{T S}$

In the case of an unstrengthened section or when strengthening occurs after reaching its moment capacity, the curvature at yielding $\chi_{y}$ may be computed as:

$-\chi_{y}=\frac{m_{R}}{E I_{1}}-\chi_{T S}$

In the case of a section which is strengthened while in the stabilized cracking regime, it is necessary to determine if the strengthening occurs before or after the existing reinforcement bars in the unstrengthened section have yielded. The curvature at which bars start to yield $\chi_{y, u b}$ in the unstrengthened section may be computed as:

$-\chi_{y, u}=\frac{\varepsilon_{y}}{\left(d_{s}-c_{1}\right)}-\chi_{T S}$

When strengthening occurs before the curvature reaches the one computed using Eq. (A.17), the behaviour is followed by a stiffer behaviour $\left(E I_{2}\right)$ and the existing reinforcement bars yield at:

$-\chi_{y, b}=\frac{\varepsilon_{y}}{\left(d_{s}-c_{2}\right)}-\chi_{T S}$

Afterwards, the behaviour becomes less stiff. The calculation of $m_{y}$ is shown next. In the case of a section that is strengthened before the ordinary reinforcement bars have yielded, $m_{y}$ may be computed as:

$m_{y}=m_{c r}+E I_{1} \cdot\left(\chi_{s t}-\chi_{1}\right)+E I_{2} \cdot\left(\chi_{y, b}-\chi_{s t}\right)$

When the section is strengthened before the stabilized cracked regime $m_{y, b}$ may be computed as:

$m_{y}=m_{c r}+E I_{2} \cdot\left(\chi_{y, b}-\chi_{1}\right)$

\section{Appendix C}

In the continuous model, the slab is modelled as an axisymmetric disk supported on a round column. The disk is divided into sector elements over the radius $r$ so that the length of each element is $\Delta r_{i}$. The forces acting on an element are shown in Fig. C- 1 . The shear force is assumed to be transferred only in radial direction while the bending moment is assumed to be transferred both in radial and tangential directions respecting the geometric compatibility:

$\chi_{t}(r)=-\frac{\psi(r)}{r}$

Calculation is started in the centre of the slab by choosing an initial radial curvature $\chi_{r, 1}$. Tangential curvature in the middle of the element can be calculated:

$\chi_{t, i}=\frac{-\psi_{i}+\chi_{r, i} \cdot \Delta r_{i} / 2}{r_{i}+\Delta r_{i} / 2}$

Tangential moment acting on the element can thereafter be found using the non-linear moment-curvature relationship from Fig. 4. The radial moment at the outer edge of the element (at $r_{i+1}$ ) can be determined from the moment equilibrium of the element around the edge at $r_{i}$ as:

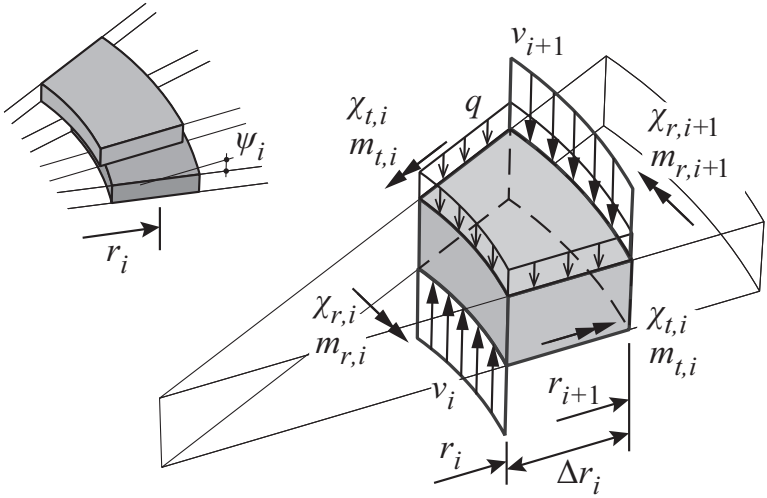

Fig. C-1. Forces acting in a slab segment.

$m_{r, i+1}=m_{r, i} \cdot \frac{r_{i}}{r_{i+1}}+m_{t, i} \cdot \frac{\Delta r_{i}}{r_{i+1}}-v_{i+1} \cdot \Delta r_{i}-q_{i} A_{i} \cdot \frac{r_{a}-r_{i}}{r_{i+1}}$

where $A_{i}$ is the area and $r_{a}$ is the location of the centre of gravity of the element. The radial curvature at the outer edge of the element can be found from the inverse of the moment-curvature relationship. The slab rotation at $r_{i+1}$ is:

$\psi_{i+1}=\psi_{i}-\frac{\chi_{r, i}+\chi_{r, i+1}}{2} \cdot \Delta r$

And the vertical displacement of a point $r_{i+1}$ can be calculated as:

$\delta_{i+1}=\delta_{i}+\frac{\psi_{i}+\psi_{i+1}}{2} \cdot \Delta r$

The calculation is continued for the next element. When the last element is reached, an edge condition is checked. For an isolated slab element, the edge condition is the equilibrium of radial moments:

$m_{r}=0$

To model a continuous slab, the radius of the axisymmetric disk is taken as half the span and the edge condition is:

$\psi=0$

If the edge condition is not satisfied, the initial assumption of the radial curvature $\chi_{r, 1}$ has to be modified. The iteration has to be performed for every different load level to obtain a loadrotation relationship.

\section{References}

[1] Wang JW, Tan KI. Punching shear behaviour of RC flat slabs externally strengthened with CFRP system. In: Proceedings of the 5th international conference on fibre-reinforced plastic for reinforced concrete structures (FRPRCS-5), vol. 2. London: Thomas Telford; 2001.

[2] Mosallam AS, Mosalam KM. Strengthening of two-way concrete slabs with FRP composite laminates. Constr Build Mater 2003;17(1):43-54.

[3] Harajli MH, Soudki KA. Shear strengthening of interior slab-column connections using carbon fiber-reinforced polymer sheets. J Compos Construct 2003;7(2):145-53.

[4] Ebead U, Marzouk H. Fiber-reinforced polymer strengthening of two-way slabs. ACI Struct J 2004;101(5):650-9.

[5] Chen Cheng-Chih, Li Chung-Yan. Punching shear strength of reinforced concrete slabs strengthened with glass fiber-reinforced polymer laminates. ACI Struct J 2005;102(4):535-42.

[6] Sharaf Mohamed H, Soudki Khaled A, Van Duse Michael. CFRP strengthening for punching shear of interior slab-column connections. J Compos Construct 2006:10.5:10-418.

[7] Rochdi EH, Bigaud D, Ferrier E, Hamelin P. Ultimate behavior of CFRP strengthened RC flat slabs under a centrally applied load. Compos Struct 2006;72(1):69-78.

[8] Suter R, Moreillon L. "Renforcement de dalles en béton contre le poinçonnement au moyen d'armatures collées" (Strengthening of concrete 
slabs to punching using bonded reinforcement). Test Report. EIA Fribourg; 2007.

[9] Kim YJ, Longworth JM, Wight RG, Green MF. Flexure of two-way slabs strengthened with prestressed or nonprestressed CFRP sheets. J Compos Construct 2008;12(4):366-74.

[10] Esfahani MR, Kianoush MR, Moradi AR. Punching shear strength of interior slab-column connections strengthened with carbon fiber reinforced polymer sheets. Eng Struct 2009;31(7):1535-42.

[11] Farghaly AS, Ueda T. Prediction of punching shear strength of two-way slabs strengthened externally with FRP sheets. J Compos Construct 2010;15(2):181-93.

[12] Abdullah A, Bailey CG, Wu ZJ. Tests investigating the punching shear of a column-slab connection strengthened with non-prestressed or prestressed FRP plates. Constr Build Mater 2013;48:1134-44.

[13] Smith ST, Teng JG. FRP-strengthened RC beams. I: review of debonding strength models. Eng Struct 2002;24(4):385-95.

[14] Muttoni A. Punching shear of reinforced concrete slabs without transverse reinforcement. ACI Struct J 2008;105(4):440-50.

[15] Kinnunen S, Nylander H. Punching of concrete slabs without shear reinforcement. Trans R Inst Technol 1960;158(112):33. Stockholm, Sweden.

[16] Fernández Ruiz M, Muttoni A, Kunz J. Strengthening of flat slabs against punching shear using post-installed shear reinforcement. ACI Struct J 2010;107(4):434-42.

[17] Inácio M, Pinho Ramos A, Faria D. Strengthening of flat slabs with transverse reinforcement by introduction of steel bolts using different anchorage approaches. Eng Struct 2012;44:63-77.

[18] Adetifa B, Polak MA. Retrofit of slab column interior connections using shear bolts. ACI Struct J 2005;102(2):238-74.

[19] Teng JG, Chen JF, Smith ST, Lam L. FRP strengthened RC structures. Wiley; 2002. p. 266.
[20] Oller Ibars E, Cobo del Arco D, Marí Bernat AR. Design proposal to avoid peeling failure in FRP-strengthened reinforced concrete beams. J Compos Construct 2009;13(5):384-93.

[21] Muttoni A, Fernández Ruiz M, Bentz EC, Foster SJ, Sigrist V. Background to the model code 2010 shear provisions - part II punching shear. Struct Concr 2013;14(3):204-14.

[22] Fernández Ruiz M, Muttoni A. Applications of critical shear crack theory to punching of reinforced concrete slabs with transverse reinforcement. ACl Struct J 2009;106(4):485-94.

[23] Sagaseta J, Muttoni A, Fernández Ruiz M, Tassinari L. Non-axis-symmetrical punching shear around internal columns of RC slabs without transverse reinforcement". Mag Concr Res 2011;63(6):441-57.

[24] Maya LF, Fernández Ruiz M, Muttoni A, Foster SJ. Punching shear strength of steel fibre reinforced concrete slabs. Eng Struct 2012;40:83-94.

[25] Clément T, Ramos AP, Fernández Ruiz M, Muttoni A. Design for punching of prestressed concrete slabs. Struct Concr 2013;14:157-67.

[26] Guandalini S. Poinçonnement symétrique des dalles en béton armé (Symmetric Punching of reinforced concrete slabs). École Polytéchinque Fédérale de Lausanne. PhD Thesis; 2005.

[27] Tassinari L. Poinçonnement non symétrique des dalles en béton armé (Nonsymmetric punching of reinforced concrete slabs). École Polytéchinque Fédérale de Lausanne. PhD Thesis; 2011.

[28] Muttoni A, Fernández Ruiz M, Einpaul J. Punching strength of actual two-way slabs. In: 4th Fib congress, Mumbai, India; 2014. p. 6.

[29] Choi JW, Kim JHJ. Experimental investigations on moment redistribution and punching shear of flat plates. ACI Struct J 2012;109(3):329-37.

[30] Eurocode 2. Design of concrete structures-part 1-1: general rules and rules for buildings EN 1992-1-1; 2004.

[31] Fib Fédération international du béton. Model Code 2010. Final Draft. Lausanne, Switzerland; 2010. p. 653. 